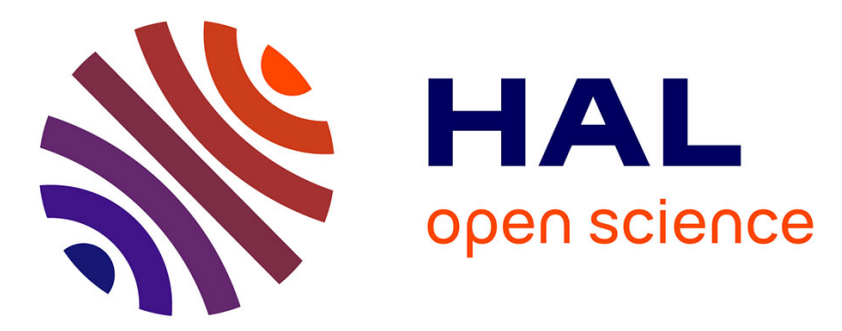

\title{
Comparison of ecosystem functional type patterns at different spatial resolutions in relation with FLUXNET data
}

Lluís Pesquer, Cristina Domingo-Marimon, Jordi Cristobal Roselló, Catherine Ottlé, Philippe Peylin, Francesca Bovolo, Lorenzo Bruzzone

\section{To cite this version:}

Lluís Pesquer, Cristina Domingo-Marimon, Jordi Cristobal Roselló, Catherine Ottlé, Philippe Peylin, et al.. Comparison of ecosystem functional type patterns at different spatial resolutions in relation with FLUXNET data. SPIE Remote Sensing, Sep 2019, Strasbourg, France. pp.8, 10.1117/12.2533049 . hal-02390697

\section{HAL Id: hal-02390697 \\ https://hal.science/hal-02390697}

Submitted on 9 Nov 2021

HAL is a multi-disciplinary open access archive for the deposit and dissemination of scientific research documents, whether they are published or not. The documents may come from teaching and research institutions in France or abroad, or from public or private research centers.
L'archive ouverte pluridisciplinaire HAL, est destinée au dépôt et à la diffusion de documents scientifiques de niveau recherche, publiés ou non, émanant des établissements d'enseignement et de recherche français ou étrangers, des laboratoires publics ou privés. 


\title{
Comparison of Ecosystem Functional Type patterns at different spatial resolutions in relation with FLUXNET data
}

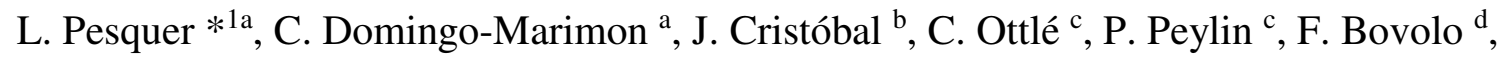 \\ L. Bruzzone ${ }^{\mathrm{e}}$ \\ ${ }^{\text {a }}$ GRUMETS research group. CREAF, Campus de Bellaterra (UAB) Edifici C 08193 Cerdanyola del \\ Vallès (Spain). \\ ${ }^{\mathrm{b}}$ University of Alaska Fairbanks (USA). \\ ${ }^{\mathrm{c}}$ Laboratoire des Sciences du Climat et de l'Environnement (France) \\ ${ }^{\mathrm{d}}$ Fondazione Bruno Kessler (Italy) \\ ${ }^{\mathrm{e}}$ Università degli studi di Trento (Italy)
}

\begin{abstract}
The present study aims at analyzing the role of spatial resolution in Ecosystem Functional Types (EFT) time series' patterns by comparing their spatial variability, retrieved at $300 \mathrm{~m}$ (MERIS products) and $30 \mathrm{~m}$ (Landsat products) of spatial resolution, with time series of Fluxnet in situ measurements, such as gross primary production (GPP) and evapotranspiration (ET).

EFT maps at both spatial resolutions for 2005 and 2009 year in Sudan study region were generated, with a classification system of 64 categories. However, the $50 \%$ of the study area was covered by four representative EFTs. The main result at fine spatial resolution, related to the 2005-2009 comparison, shows a clear pattern of vegetation with high productivity and low seasonality in both years. At coarse spatial resolution, EFTs located in shrublands or forests regions are more difficult to be clearly detected.

The presented methodology is absolutely replicable for using Sentinel-2 (MSI) images and Lansat-8 (OLI) in cases where the data availability of fluxnet database reaches the Sentinel-2 and Landsat- 8 active period.
\end{abstract}

Keywords: Spatial Resolution, Ecosystem Functional Type, FLUXNET, Vegetation Index, time series

\section{INTRODUCTION}

Plant Functional Types (PFTs) and Ecosystem Functional Types (EFTs) are different attempts for characterizing biodiversity elements as functional units by representing the complexity of species diversity in aggregated categories and its dynamics. Both approaches allow assessing global climate change impacts [1]. PFT approach defines groups of plants that share similar functional features and it is based on composition [2]. Alternatively, the EFT aims at a functional classification of ecosystems so that groups of ecosystems are based on the functional characteristics shared in relation with the amount and time of the exchanges of matter and energy between the biota and the physical environment [3]. Among others, one of the main approaches to the definition of the EFT relies on the use of seasonal dynamics analysis of vegetation spectral indices derived from Earth Observation (EO) data that can provide key functional aspects of ecosystems related to primary production, water, carbon exchanges and surface energy balance [4]. Following this methodology, EFT are obtained from the combination of three components of time series' variables derived from vegetation indices (VI): seasonality, phenology and productivity. Such variables collect crucial functional aspects of ecosystems and provide relevant information, useful as input to climate models. Since the satellite data is the source of

1 *1.pesquer@creaf.uab.cat; phone +34 935811666; fax 1 +349835814151; http://www.grumets.uab.cat/ 
these vegetation indices components, the spatial resolution of the remote sensing imagery could play a relevant role in climate models, both at local or regional scales. Fluxnet is a global network across the globe of micrometeorological flux measurements that measure the exchange of carbon dioxide, water vapor, and energy between the biosphere and the atmosphere [5].

In most of the published studies [1][3], EFTs are generated from medium or low spatial resolution, from a few kilometers to a few hundred meters. The present study achieves a finer spatial resolution $(30 \mathrm{~m})$, thus the exploration of the role of the spatial resolution in the accurate generation of EFT and their relation to the in-situ measurements and the matching between this in-situ EO and the remote sensing VI products [6] are the main goals.

\section{MATERIALS}

\subsection{Study zone}

The study zone is an arid desert region located at west Sahel, in Sudan (bounding box. 29 $49^{\prime} 39.44^{\prime \prime} 31^{\circ} 57^{\prime} 43.18^{\prime \prime}, 12^{\circ}$ $3^{\prime} 39.64^{\prime}, 3^{\circ} 57^{\prime} 35.31^{\prime \prime}$ longitude/ latitude WGS84) (see Figure 1). This region is one of the study regions of the ESA High-Resolution Landcover CCI project ${ }^{2}$ and in the area there is a Fluxnet tower (SD-Dem / Demokeya) that provides the required time series of in-situ data essential to carry out this research.

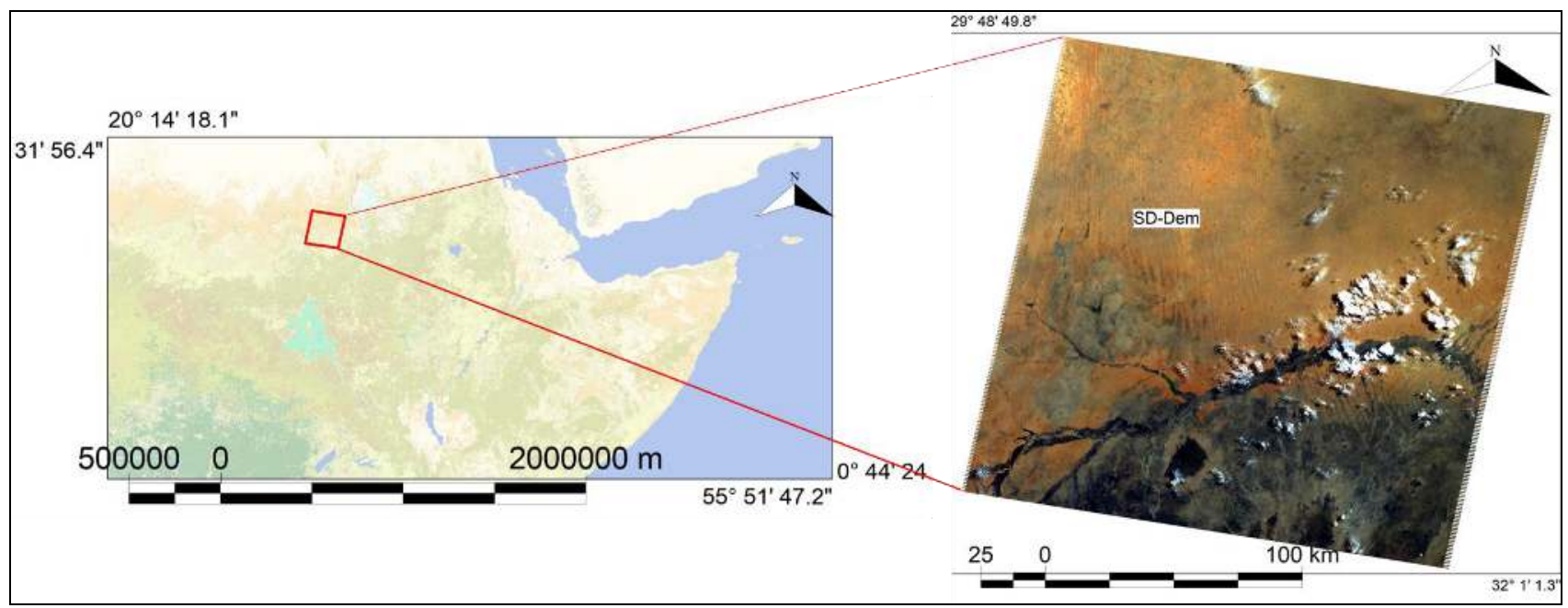

Figure 1.Location of the study area, at west Sahel (left) and location of Fluxnet tower on a TM Landsat scene (3-2-1 RGB composition of 07/06/2009) (right). The study area encompassed a Landsat TM and ETM path 174, row 51 following WRS2 tile system.

\subsection{Data}

a) Remote sensing time series

High resolution Landsat-5 TM and Landsat-7 ETM Level-2 surface reflectance $(30 \mathrm{~m})$ official products were obtained from the website of the USGS through EarthExplorer tool [7] on demand. Medium resolution time series of Envisat MERIS Full Resolution 7-day composites surface reflectance product [8] (300 m) for tiles h41v15 and h42v15 were provided by the Land Cover CCI project ${ }^{3}$.

b) Fluxnet

Data from the Demokeya flux station (SD-DEM, lat/long: 13.2829, 30.4783 and elevation of $500 \mathrm{~m}$ a.s.l.) in Sudan was downloaded from the Fluxdata gateway ${ }^{4}$. This flux station is located in savannas with herbaceous and other understory

\footnotetext{
${ }^{2}$ http://cci.esa.int/HRLandcover

${ }^{3}$ https://www.esa-landcover-cci.org/

${ }^{4}$ https://fluxnet.fluxdata.org/
} 
systems, and with forest canopy cover between 10-30\% where the forest cover height exceeds 2 meters. Annual mean temperature is about $26{ }^{\circ} \mathrm{C}$ and annual precipitation is around $320 \mathrm{~mm}$. The times series available for the SD-Dem Fluxnet site is from 2005 to 2009. This period has determined the two comparison epochs of the EFT maps and the corresponding time series of the remote sensing VI products. From this time range the daily FULLSET Data Product was downloaded.

\section{METHODOLOGY}

\subsection{Remote sensing data processing}

Considering the availability of the Fluxnet data in the study region, two representative years have been selected: 2005 and 2009. Correspondingly, two EFTs map have been produced at the two spatial resolutions of Landsat and MERIS 30 and $300 \mathrm{~m}$, respectively. For the generation of each EFT map, a regular time series of a vegetation index is required, for instance [9] uses a 16-day composite MODIS VI product while the [10] times series is monthly. For Landsat times series were directly obtained from the available land surface products for which clouds were removed thanks to its ancillary data. In case of missing data for a giving month of year 2005 or year 2009, a synthetic image was created (see details in Table 1). Additionally, for the ETM+, due to the SLC-off malfunction [11] a simple method to fill missing values was applied (covered with the nearer date). In summary, Table 1 shows the images and composite methodology used: $C V R$ or $A V G$ :

- $\quad C V R$ is the cover map algebra function where the results collect the valid values of the first image it replaces their missing values with values of the second argument.

- $A V G$ is the average of the two implied images.

Table 1. Set of images that compose Landsat time series for EFT for 2005 and 2009 periods

\begin{tabular}{|l|l|l|l|l|}
\hline & \multicolumn{2}{|c|}{2005} & & Sensor \\
\hline Month & Dates 2005 & Sensor & Dates 2009 & TM \\
\hline January & CVR $(27.01 .2005,11 / 01 / 2005)$ & ETM+ & $17 / 01 / 2010$ & TM \\
\hline February & CVR $(28 / 02 / 2005,12 / 02 / 2005)$ & ETM+ & $02 / 02 / 2010$ & ETM+ \\
\hline March & $16 / 03 / 2005$ & ETM+ & CVR $(27 / 03 / 2009,11 / 03 / 2009)$ & ETM+ \\
\hline April & CVR $(17 / 04 / 2005,01 / 04 / 2005)$ & ETM+ & $28 / 04 / 2009$ & TM \\
\hline May & $16 / 05 / 2004$ & ETM+ & $19 / 05 / 2008$ & TM \\
\hline June & $01 / 06 / 2004$ & ETM+ & $07 / 06 / 2009$ & ETM+ \\
\hline July & AVG $(01 / 06 / 2004,20 / 08 / 2004)$ & ETM+ & CVR $(14 / 07 / 2008,30 / 07 / 2008)$ & TM \\
\hline August & $20 / 08 / 2004$ & ETM+ & $29 / 08 / 2010$ & TM \\
\hline September & CVR $(08 / 09 / 2005,24 / 09 / 2005)$ & ETM+ & $24 / 09 / 2008$ & ETM+ \\
\hline October & CVR $(10 / 10 / 2005,26 / 10 / 2005)$ & ETM+ & CVR $(05 / 10 / 2009,21 / 10 / 2009)$ & TM \\
\hline November & CVR $(11 / 11 / 2005,27 / 11 / 2005)$ & ETM+ & $30 / 11 / 2009$ & TM \\
\hline December & CVR $(13 / 12 / 2005,29 / 12 / 2005)$ & ETM+ & $16 / 12 / 2009$ & \\
\hline
\end{tabular}

The original medium resolution time series is a regular series of 7-day product (see description in previous section) that has only been reprojected (from lat/lon to UTM) and both tiles have been mosaicked and clipped to study boundary area defined by the Landsat scene. Dates in $\mathrm{dd} / \mathrm{mm} / \mathrm{yyyy}$.

For each date, the Normalized Difference Vegetation Index (NDVI) [12] has been computed and the three quantitative components of the EFTs, productivity (NDVI-I), seasonality (sCV) and phenology (MMAX) derived. Productivity is the annual mean of the VI. Seasonality is computed as the coefficient of variation of the NDVI seasonal curve (standard 
deviation / mean), while Phenology is represented by the date of the maximum NDVI. Each component is divided in 4 intervals according to its distribution (Table 2). Finally, these 3 components are combined to generate a categorical combination, $6(4 \times 4 \times 4)$ possible different categories (sometimes some combination does not appear).

Table 2. Definition of intervals for the three components of the EFTs:

\begin{tabular}{|c|c|c|c|c|c|}
\hline & & & $\mathrm{m}$ & & \\
\hline & & low & high & low & high \\
\hline & $\mathbf{A}$ & 0.049999999 & 0.138572052 & -0.082468495 & 0.171461716 \\
\hline$\stackrel{\vec{\Sigma}}{\Xi}$ & B & 0.138572052 & 0.152677923 & 0.171461716 & 0.186968684 \\
\hline 氖 & $\mathrm{C}$ & 0.152677923 & 0.175425783 & 0.186968684 & 0.228663057 \\
\hline 这定范 & D & 0.175425783 & 1.0 & 0.228663057 & 0.522216083 \\
\hline せた & d & 0.0 & 0.253068298 & -5.80602456 & 0.273877174 \\
\hline$\Xi \stackrel{\pi}{\Xi} \Xi$ & $\mathbf{c}$ & 0.253068298 & 0.348354489 & 0.273877174 & 0.330920547 \\
\hline 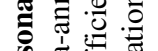 & $\mathbf{b}$ & 0.348354489 & 0.470573425 & 0.330920547 & 0.395987660 \\
\hline ڤँ & $\mathbf{a}$ & 0.470573425 & 1.45412338 & 0.39598766 & 24.26265540 \\
\hline & 1 & $21 / 06$ & $21 / 09$ & $21 / 06$ & $21 / 09$ \\
\hline 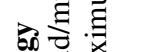 & 2 & $22 / 09$ & $31 / 12$ & $22 / 09$ & $31 / 12$ \\
\hline 冚 & 3 & $01 / 01$ & $15 / 04$ & $01 / 01$ & $15 / 04$ \\
\hline 至 & 4 & $16 / 04$ & $20 / 06$ & $16 / 04$ & $20 / 06$ \\
\hline
\end{tabular}

\subsection{Flux data processing}

From the daily FULLSET Data Product Flux data evapotranspiration (ET) and gross primary productivity (GPP) were compared to EFT's. Daily ET $\left(\mathrm{mm} \cdot\right.$ day $\left.^{-1}\right)$ was computed as a residual using quality controlled data for sensible heat flux, H, (tagged as H_F_MDS in the dataset), soil heat flux, G, (tagged as G_F_MDS in the dataset) and net radiation, Rn, (tagged as NETRAD) following Eq 1 and the converted to $\mathrm{mm} \cdot \mathrm{day}^{-1}$.

$$
\mathrm{LE}_{\mathrm{res}}=\mathrm{Rn}-\mathrm{H}-\mathrm{G}
$$

GPP $\left(\mathrm{g} \cdot \mathrm{Cm}^{-2} \cdot \mathrm{d}^{-1}\right)$ was computed according [13] by averaging the night-time GPP retrieval method (GPP_NT_VUT_REF) and the day-time GPP retrieval method (GPP_DT_VUT_REF).

At local neighbouring analysis of EFTs around the fluxnet site, the present work assumed a simplified homogeneous and constant footprint according to the tower height for pixel selection.

\section{RESULTS AND DISCUSSION}

\subsection{Results at $30 \mathrm{~m}$ of spatial resolution}

In 2005, the Sudan area covered a high spatial variability in the NDVI-I, ranging from 0.05 to almost 0.63 . The highest values were reached in the reduced areas of mosaicked cropland. The semiarid areas of grasslands and savannas and bare soils presented the lowest values. The area was quite variable in terms of seasonality (sCV). sCV was the highest at areas with mosaic vegetation with croplands (20\%-50\%) and mix of forest or shrublands, while it was getting lower as the mixed areas were turning into herbaceous vegetation (savannas). Finally, almost all the area presented a clear NDVI maximum during June-September except some part of the savanna that showed their maximum during SeptemberDecember. All 64 possible EFT were represented in 2005, but the $50 \%$ of the territory was covered by classes $\operatorname{Dal}(15.6 \%), \operatorname{Adl}(11.9 \%), \operatorname{Cbl}(10.3 \%), B c 1(9.6 \%)$ (Table 3). All them agreed on the date of the maximum but differed 
on the productivity and seasonality: very productivity but low seasonality, low productivity and high seasonality, or medium productivity and medium seasonality.

In 2009, the spatial variability in the NDVI-I was a bit lower than in 2005 (ranging from 0.05 to 0.57 ). The highest values were reached in both the reduced areas of mosaicked cropland and top parts of forested/shrublands area. The semiarid areas of grasslands and savannas and bare soils presented the lowest values. $\mathrm{sCV}$ was the highest at areas where sparse vegetation was predominant., while it was lower as the mixed areas that were turning into herbaceous vegetation (savannas). Contrasting with 2005 results, the area presented two predominant periods of maximum NDVI during JuneSeptember and September-December. All 64 possible EFT were also represented in 2009. The most representative category was again $\mathrm{Dal}(19.5 \%)$ followed by $\mathrm{Da} 2(11.4 \%)$ meaning that the productivity and seasonality was kept but that the phenology was moved towards the end of the year (September-December). The rest of the area presented a more variable pattern, with no clear predominance of any other category.

\subsection{Results at $300 \mathrm{~m}$ of spatial resolution}

In 2005, MERIS derived data presented a similar behavior to Landsat derived data. Indeed, NDVI-I presented lower range than for Landsat at the same period (0.05-0.52). Highest values were clearly located at areas of mosaic forest or shrubland $(50-70 \%)$ / grassland $(20-50 \%)$ while low values corresponded to savannas. Regarding seasonality, highest values corresponded to mosaic areas of forest, shrublands and croplands. The peak of the maximum NDVI was mainly during the period June-September. Contrary to the $30 \mathrm{~m}$ resolution maps, only 46 EFT categories were present and 18 were inexistent. The EFTs that predominated the area were the same as for the $30 \mathrm{~m}$ map but with different representativeness: $A d l$ (13.8\%), $\mathrm{Dal}(11.9 \%), B c 1$ (9.4\%) and $C b 1$ (9.3\%).As seen by Landsat, all them agreed on the date of the maximum but differed on the productivity and seasonality: low productivity and high seasonality, high productivity but low seasonality, or medium productivity and medium seasonality.

In 2009, the NDVI-I range was again lower than the one for 2005 (0.05-0.45). In this case, maximums were located at the areas with shrublands and forest mixed with grasslands while low values corresponded to savannas. sCV was slightly lower for 2009, with highest values corresponding to mosaic areas of forest, shrublands and croplands. The peak of the maximum NDVI was mainly during the period June-September. In this case, only 39 categories out of 64 were present in the output. The $50 \%$ of the study area was covered by 4 EFT: Dal (16.31\%) followed by Adl (15.0\%), Bcl (10.8\%) and $\mathrm{Cb} 1(8.1 \%)$. All they agreed on the date of the maximum but the most representative one was characterized by a high productivity and low seasonality (the opposite of 2005).

Table 3. Most representative EFT categories in two periods and two spatial resolutions

\begin{tabular}{|c|c|c|c|}
\hline $30 \mathrm{~m} 2005$ & 30 m 2009 & 300 m 2005 & $300 \mathrm{~m} 2009$ \\
\hline Da1 (15.6\%) & $\operatorname{Da} 1(19.5 \%)$ & $\operatorname{Ad} 1(13.8 \%)$ & Da1 (16.3\%) \\
\hline Ad1 (11.9\%) & $\mathrm{Da} 2(11.4 \%)$ & Da1 (11.9\%) & Ad1 (15.0\%) \\
\hline Cb1 (10.3\%) & $\operatorname{Cc} 2(8.1 \%))$ & $\operatorname{Bc} 1(9.4 \%)$ & $\operatorname{Bc1}(10.8 \%)$ \\
\hline $\operatorname{Bc} 1(9.6 \%)$ & Db1 $(7.9 \%)$ & Cb1 $(9.3 \%)$ & $\operatorname{Cb} 1(8.1 \%)$ \\
\hline
\end{tabular}




\section{EFT $200530 \mathrm{~m}$}
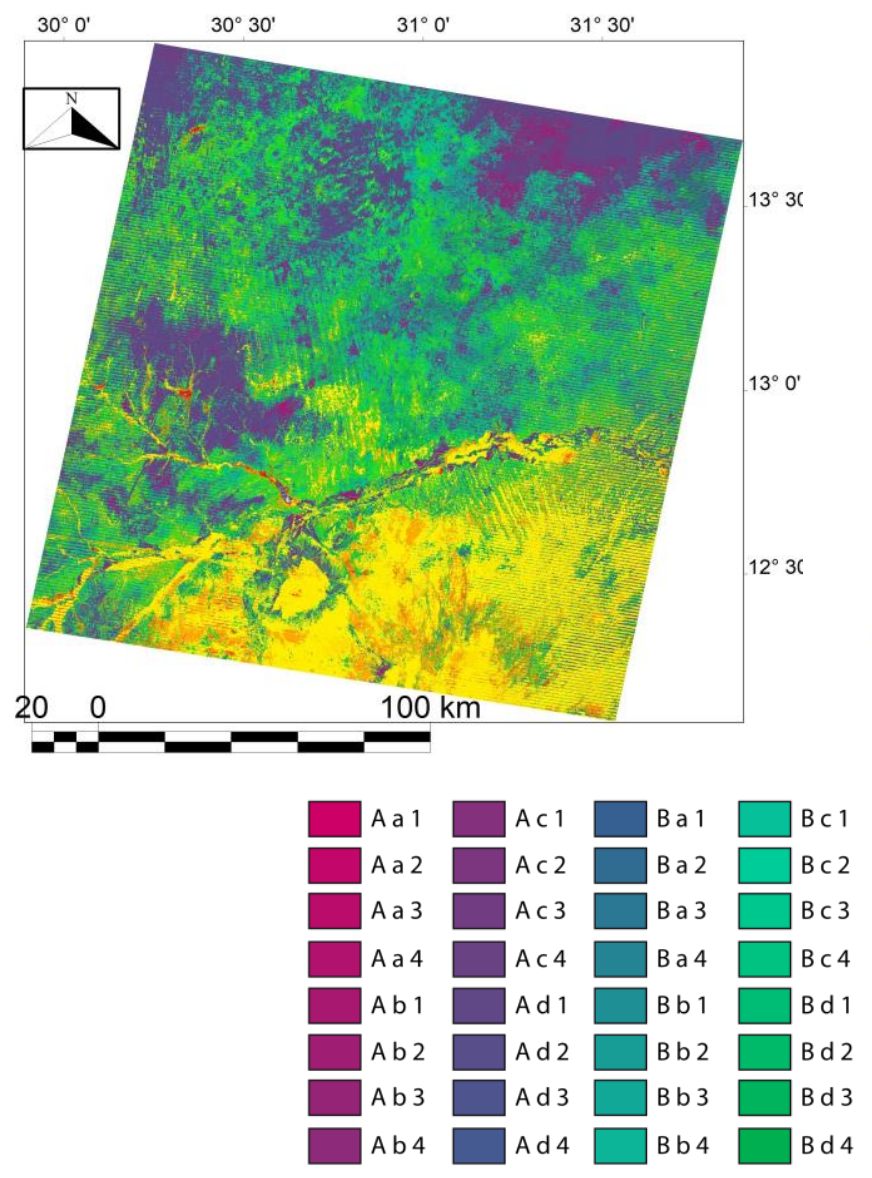

EFT 2005300 m

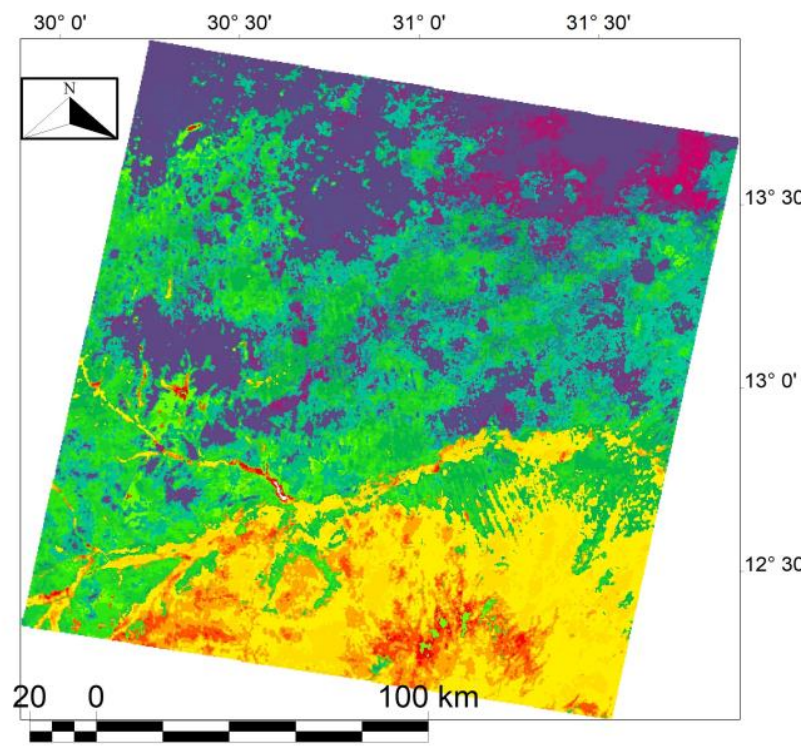

\section{EFT $200930 \mathrm{~m}$}

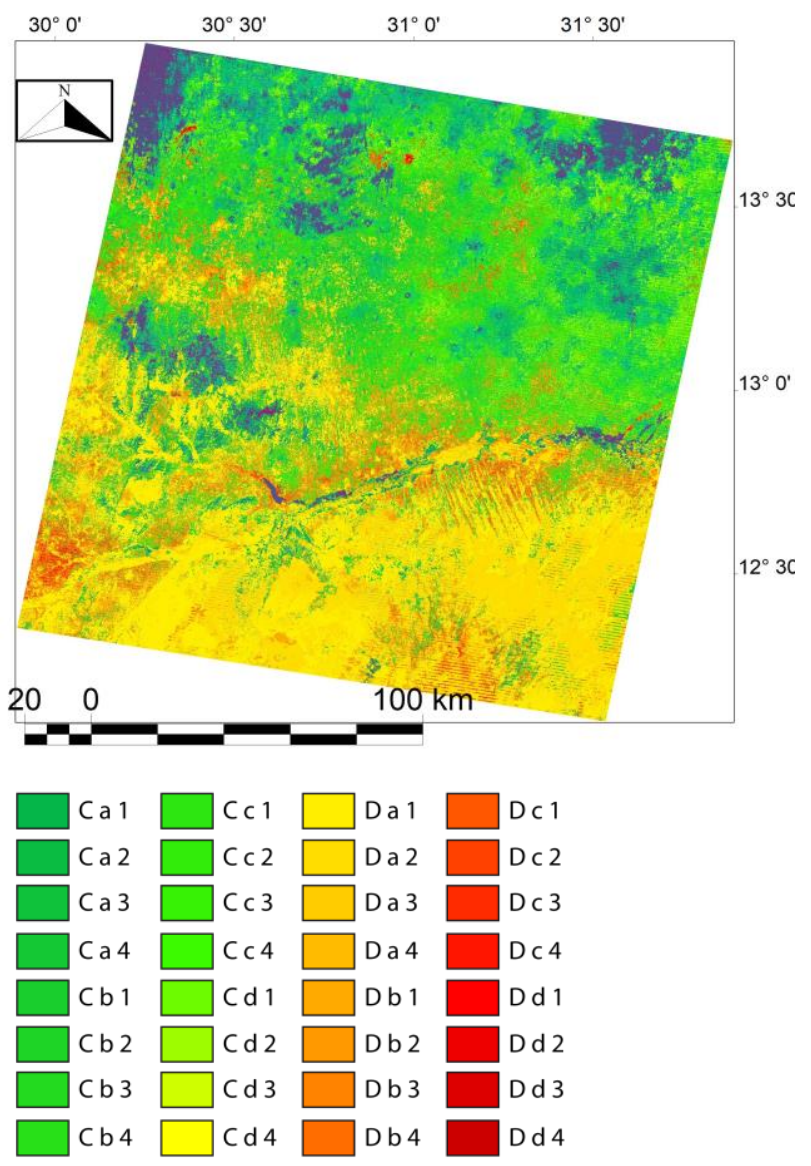

\section{EFT $2009300 \mathrm{~m}$}

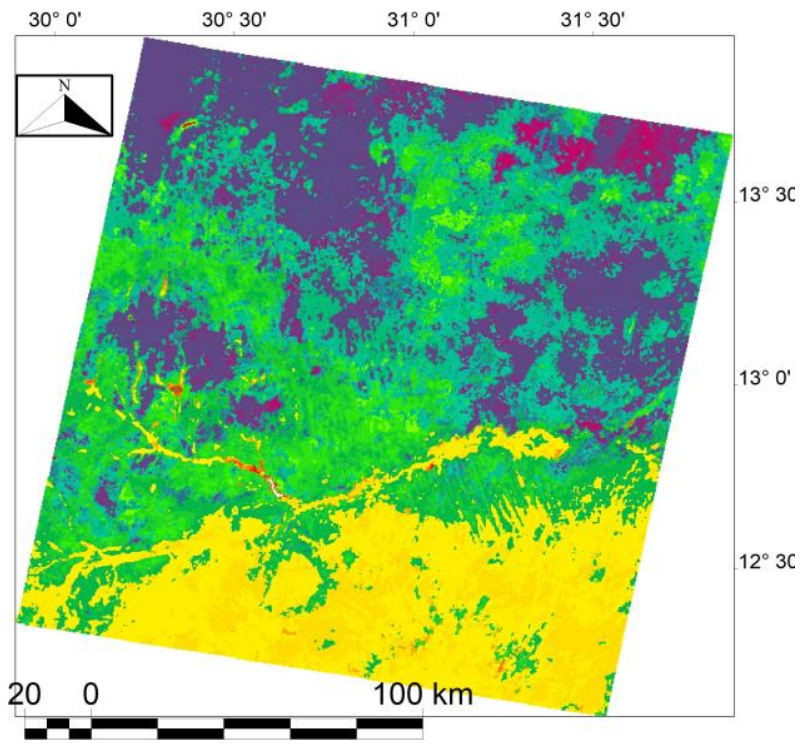

Figure 2:. Top Left: Map of 2005 at 30 m. Top Right: Map of 2009 at 30 m. Bottom Left: Map of 2005 at 300 m. Bottom Right: Map of 2009 at $300 \mathrm{~m}$. 


\subsection{ETF comparison with Fluxnet data}

ET showed a different behavior in both years due to an early rain season in 2005 (Figure 3). Around $45 \mathrm{~mm}$ of rainfall were accumulated until DOY 180 in 2005 while in 2009 were only $7 \mathrm{~mm}$. This rainfall had an impact in the herbaceous vegetation cycle around the flux tower (see detail in Figure 4) leading to higher rates of ET in 2005, probably because an early leaf-out. However, in 2009 ET started to increase around 20 days after DOY 180 in 2005 suggesting a different vegetation cycle with a late leaf-out. This vegetation cycle behavior was captured by the EFT where in 2005 the study area presented a clear NDVI maximum during June-September while in 2009 this maximum occurred later. GPP confirms this behavior at 2009; unfortunately, this analysis could not carry on in 2005, due GPP in-situ data problems.
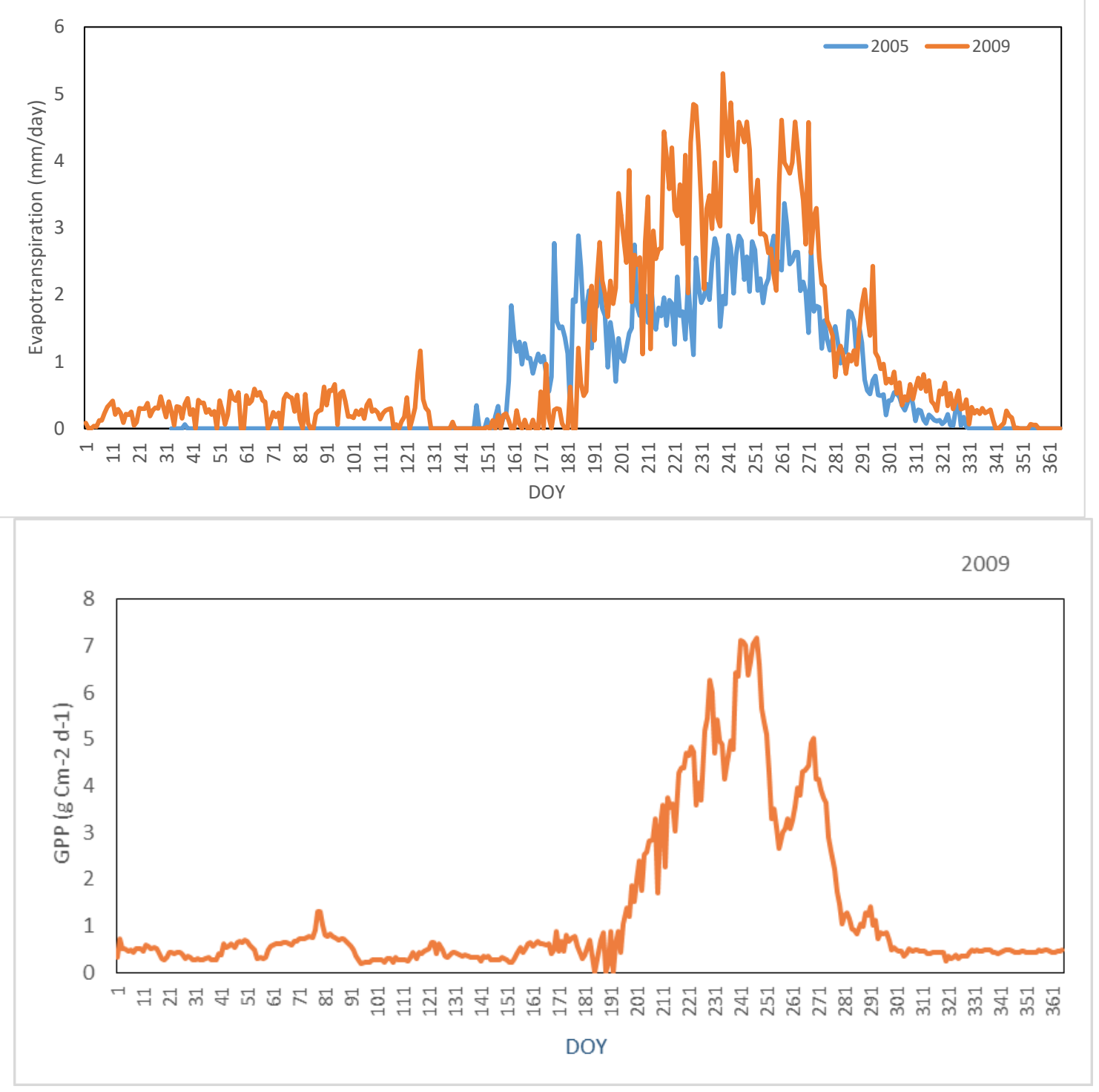

Figure 3: ET daily time series data for 2005 and 2009 and GPP for 2009. 

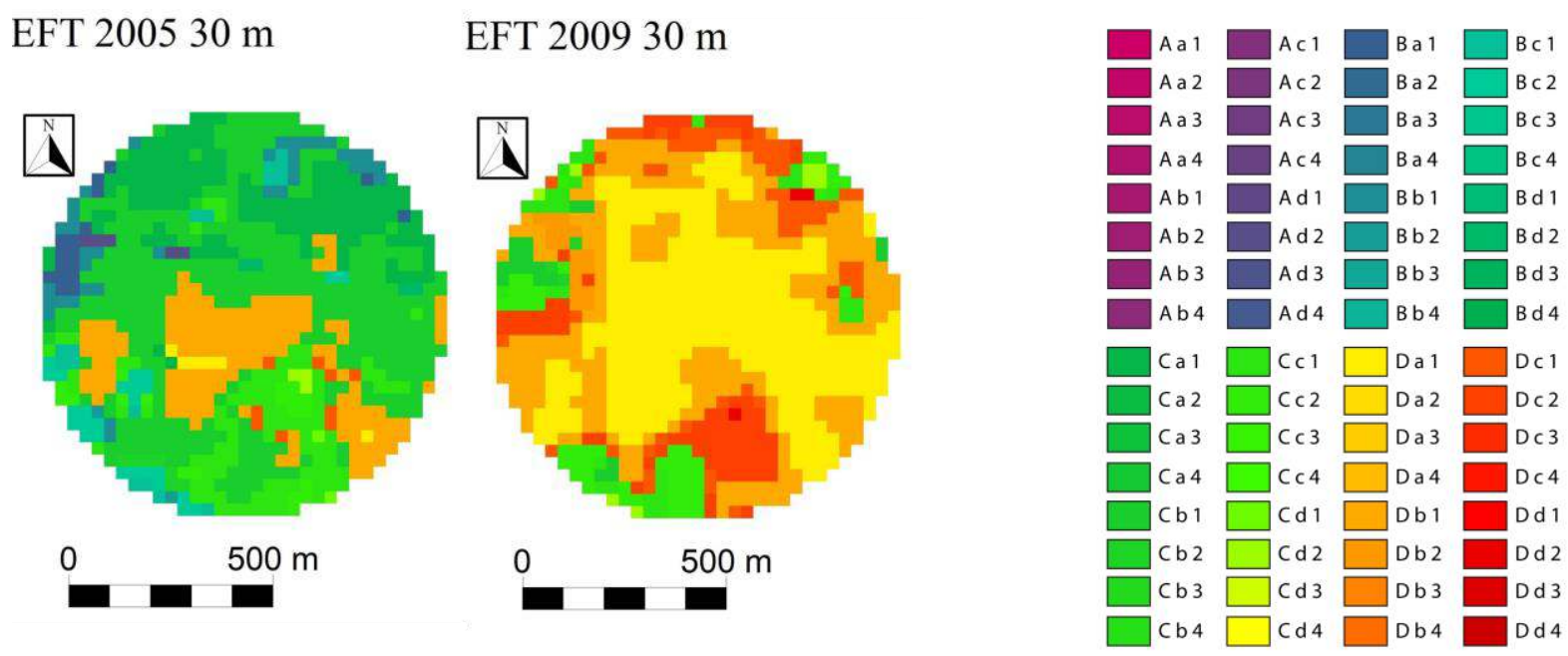

Figure 4: EFT maps in the neighboring of the fluxnet SD-Dem site.

\section{CONCLUSIONS}

The present work shows the needed synergy between remote sensing and in-situ observations for the Earth Observation systems, both supports complement with other and the understanding of the spatial patterns at different spatial resolutions of the remote sensing images helps to link them to the in-situ observations.

At fine spatial resolution, the 2005-2009 comparison shows a clear pattern of vegetation with high productivity and low seasonality in both years but in 2009 areas that in 2005 had low productivity and high seasonality tend to increase productivity. At coarse spatial resolution, the representativeness of category Adl in 2005 is higher than the same period monitored at finer resolution. At $300 \mathrm{~m}$, shrublands or forests are more difficult to be clearly detected and the satellite signal of the grasslands in between shrublands is stronger. In addition, the coarse resolution is also the reason why maximum NDVI-I in 2009 was located in areas of shrublands mixed with grasslands instead of areas of croplands again, difficult to being differentiated at $300 \mathrm{~m}$ spatial resolution.

Indeed, the present study contributes to the product assessment tasks of the ESA High-Resolution Land Cover CCI project $^{5}$ that investigates the contribution of the spatial resolution of remote sensing products (land cover, land cover change, VI, etc.) in climate modeling.

As future work, the present method is going to evaluate in additional sites located in very different biomes and different expected EFT ranges and patterns. For cases where the data availability of fluxnet database reaches the Sentinel-2 period, the high resolution time series will be mainly composed by Sentinel-2, and complemented with Landsat-8 images if was necessary. Additionally, a more accurate methodology for filling the ETM+ SLC-off will be applied, for instance [14] in a geostatistical approach.

\section{ACKNOWLEDGMENTS}

This work has been partially funded by the ESA CCI-PRGM-EOPS-SW-17-0032 High Resolution Land Cover ECV project, by the Spanish MCIU Ministry through the NewForLand research project (RTI2018-099397-B-C21/C22 MCIU/AEI/ERDF, EU) and by the Catalan Government [SGR2014-1491]. We would like to acknowledge ESA and USGS for the freely acquisition of satellite imageries from their archive. This work used eddy covariance data acquired and shared by the FLUXNET community, including these networks: AmeriFlux, AfriFlux, AsiaFlux, CarboAfrica, CarboEuropeIP, CarboItaly, CarboMont, ChinaFlux, Fluxnet-Canada, GreenGrass, ICOS, KoFlux, LBA, NECC,

${ }^{5}$ http://cci.esa.int/HRLandcover 
OzFlux-TERN, TCOS-Siberia, and USCCC. The ERA-Interim reanalysis data are provided by ECMWF and processed by LSCE. The FLUXNET eddy covariance data processing and harmonization was carried out by the European Fluxes Database Cluster, AmeriFlux Management Project, and Fluxdata project of FLUXNET, with the support of CDIAC and ICOS Ecosystem Thematic Center, and the OzFlux, ChinaFlux and AsiaFlux offices.

\section{REFERENCES}

[1] Ivits, E., Cherlet, M., Horion, S. and Fensholt, R., "Global Biogeographical Pattern of Ecosystem Functional Types Derived From Earth Observation Data" Remote Sensing 5, 3305-3330 (2013).

[2] Noble, I.R. and Gitay H., "A functional classification for predicting the dynamics of landscapes" Journal of Vegetation Science 7, 329-336 (1996)

[3] Alcaraz, D., Paruelo, J. and Cabello, J., "Identification of current ecosystem functional types in the Iberian Peninsula" Global Ecology and Biogeography 15, 200-212 (2006).

[4] Paruelo, J.M., Jobbágy, E.G., Sala, O.E., "Current distribution of ecosystem functional types in temperate South America” Ecosystems 4 (7), 683-698 (2001).

[5] Baldocchi, D., Falge, E., Gu, L., Olson, R., Hollinger, D., Running, S., Anthoni, P., Bernhofer, C., Davis, K., Evans, R., Fuentes, J., Goldstein, A., Katul, G., Law, B., Lee, X., Malhi, Y., Meyers, T., Munger, W., Oechel, W., Paw, K. T., Pilegaard, K., Schmid, H. P., Valentini, R., Verma, S., Vesala, T., Wilson, K., and Wofsy, S., "FLUXNET: A New Tool to Study the Temporal and Spatial Variability of Ecosystem5 Scale Carbon Dioxide, Water Vapor, and Energy Flux Densities" Bulletin of the American Meteorological Society 82, 2415-2434 (2001).

[6] Balzarolo, M., Vicca, S., Nguy-Robertson, A.L., Bonal, D., Elbers, J.A., Fu, Y.H., Grünwald, T., Horemans, J.A., Papale, D., Peñuelas J., Suyker, A. and Veroustraete F., "Matching the phenology of Net Ecosystem Exchange and vegetation indices estimated with MODIS and FLUXNET in-situ observations" Remote Sensing of Environment 174, 290-300 (2016)

[7] USGS (United States Geological Survey). "EarthExplorer download tool". Available online: https://earthexplorer.usgs.gov/ (accessed on 26/06/2019).

[8] Defourny, P., Santoro, M., Kirches, G., Wevers, J., Boettcher, M., Brockmann, C., Lamarche, C., Bontemps, S. and Moreau, I., "Land Cover CCI Product User Guide v2.0" UCL-Geomatics (2017).

[9] Alcaraz, D., Paruelo, J.M., Epstein, H.E. and Cabello, J., "Environmental and Human Controls of Ecosystem Functional Diversity in Temperate South America” Remote Sensing 5, 127154 (2013).

[10] Villarreal, S., Guevara, M, Alcaraz, D., Brunselle, N.A., Hayesf, D., Loescherg, H.W. and Vargasa, R., "Ecosystem functional diversity and the representativeness of environmental Agricultural and Forest Meteorology networks across the conterminous United States" Agricultural and Forest Meteorology 262, 423-433 (2016).

[11] USGS (United States Geological Survey), "Preliminary Assessment of Landsat 7 ETM+ Data Following Scan Line Corrector Malfunction". http://landsat.usgs.gov/documents/SLC off_Scientific Usability.pdf (2003). (accessed 17/07/2019)

[12] Rouse, J.W., Haas, R.H., Schell, J.A. and Deering, D.W., "Monitoring Vegetation Systems in the Great Plains with ERTS" 3rd ERTS Symposium, NASA SP-351, Washington DC, 10-14 December 1973, 309-317 (1973).

[13] Joiner, J., Yoshida, Y., Zhang, Y., Duveiller, G., Jung, M., Lyapustin, A., Wang, Y. and Tucker, J.C.. "Estimation of Terrestrial Global Gross Primary Production (GPP) with Satellite Data-Driven Models and Eddy Covariance Flux Data" Remote Sensing 10 (2018).

[14] Pringle, M.J., Schmidt, M. and Muir, J.S., "Geostatistical interpolation of SLC-off Landsat ETM+ images" ISPRS Journal of Photogrammetry and Remote Sensing 64(6) 654-664 (2009). 